\title{
Improvement of the Toughness and Crack Propagation Resistance Properties of Poly(Phenylene Sulfide)
}

\author{
B. Cetin, A.E. Sahin, N.G. Karsli, T. Yilmaz*, T. Sinmazcelik and I. Curgul \\ Kocaeli University, Mechanical Engineering Department, Umuttepe Campus, 41380 Izmit, Turkey
}

Poly(phenylene sulfide) (PPS) is a high-performance thermoplastic engineering polymer, which exhibits outstanding properties such as electrical insulation, dimensional and thermal stability, chemical resistance, etc. In addition to this, PPS has a high degree of crystallinity and it exhibits good physical properties at elevated temperatures. Owing to these properties, PPS is widely used in electrical and electronic components, automobile industry and mechanical applications. These outstanding properties of PPS can be attributed to its chemical structure, composed of phenyl groups linked by a sulfur atom, which gives rigidity to the chain. On the other hand, the brittleness with low elongation strain, toughness and crack propagation resistance also restricts its further applications. Several methods are used to overcome these undesirable properties of PPS. Blending of PPS with other polymers is one of these methods. In this study, Ethylene-Acrylic Ester-Glycidyl Methacrylate terpolymer (Lotader ${ }^{\circledR}$-AX8900) was used to improve the toughness and crack propagation resistance properties of PPS. For this purpose, PPS/Lotader $(0,2,5,10 \mathrm{wt} . \%$ Lotader $)$ blends were prepared at various compositions. The blends were manufactured using laboratory scale twin screw extruder and injection molding machine. Mechanical properties of blends were investigated by using tensile test method. In addition to this, crack propagation and toughness of samples were investigated by using essential work of fracture (EWF) method. As a result of this study, it was found that Lotader addition significantly increases the toughness and crack propagation resistance of PPS.

DOI: 10.12693/APhysPolA.129.683

PACS/topics: 81.05.Qk, 62.25.Mn, 62.20.mm

\section{Introduction}

Poly (phenylene sulfide) (PPS) is a semi-crystalline high-performance thermoplastic polymer, composed of phenyl rings linked by sulphur atoms [1,2]. PPS is a desired polymer in industry because of its unusual characteristics such as nonflammability, dimensional stability, chemical and thermal stability, high hardness, rigidity, service temperature and easy molding [3]. PPS is used as raw material for automotive industry (exhaust systems, pumps, valves etc.), electrics/electronics industry (plug socket, switch, bobbin, relay etc.), aircrafts and space ships and some other industries [1, 4]. PPS offers lots of advantages to engineers and scientists such as easy molding, testing and low cost of manufacture. However, in addition to excellent properties of PPS, it has some drawbacks. The most important ones are its brittleness and high cost of raw material. To overcome these drawbacks there are many studies aimed to improve its toughness and to reduce its cost [5].

Blending and reinforcing methods are frequently used to improve the toughness, wear and friction properties of PPS and to reduce its cost. For this reason there are some studies which have investigated these properties of PPS and of its blends $[3,6]$. Especially, blending of PPS with another polymer is one of the important ways to improve its toughness and to reduce its cost.

*corresponding author; e-mail: taner.yilmaz@kocaeli.edu.tr
Ethylene-acrylic ester-glycidyl methacrylate terpolymer is a random terpolymer. Acrylic ester groups in this terpolymer provide softness and polarity and enable high thermal stability during processing. The high content of acrylic ester in terpolymer leads to high flexibility and high impact absorption behavior. In addition to this, glycidyl methacrylate groups provide reactivity with $\mathrm{OH}$, $\mathrm{COOH}$ and $\mathrm{NH}_{2}$ groups and this leads to optimal dispersion during melt mixing with engineering thermoplastics. By this means, ethylene-acrylic ester-glycidyl methacrylate terpolymer exhibits good adhesion and interaction with PPS [7]. These properties of ethylene-acrylic esterglycidyl methacrylate terpolymer make it suitable for improving impact toughness of engineering polymers that are used in automotive and electronic industry [8].

PPS/ethylene-acrylic ester-glycidyl methacrylate terpolymer blends were prepared in this study in order to improve the toughness of PPS. Tensile test and essential work of fracture (EWF) method were used to evaluate the mechanical properties and fracture toughness of blends. Consequently, optimum amount of terpolymer was determined according to mechanical test results.

\section{Materials and methods}

\subsection{Materials}

Poly(phenylene sulfide) was supplied from Ticona company, Taunus, Germany under the Fortron 1200L1 trade name. Lotader AX8900 random terpolymer of ethyleneacrylic ester-glycidyl methacrylate was obtained commercially from Arkema Functional Polyolefins, Istanbul, Turkey. 


\subsection{Preparation of blends}

A laboratory scale twin screw co-rotating extruder was used for compounding of PPS/LOTADER blends. The compounding ratios of components in the blends and code names of specimens are given in Table I. Compounding was conducted at $315^{\circ} \mathrm{C}$ barrel temperature, $100 \mathrm{rpm}$ screw speed and constant residence time of $3 \mathrm{~min}$. Extruded compounds were subsequently injection molded with a laboratory scale injection molding machine. The barrel temperature and mold temperature were $315^{\circ} \mathrm{C}$ and $80^{\circ} \mathrm{C}$ respectively. These temperatures were determined referring to previous studies.

\section{TABLE I}

Compounding ratios of components and code names of specimens.

\begin{tabular}{c|c|c}
\hline \hline PPS/LOTADER & PPS & LOTADER \\
AX8900 & weight [\%] & weight [\%] \\
\hline PPS & 100 & 0 \\
PPS_2L & 98 & 2 \\
PPS_5L & 95 & 5 \\
PPS_10L & 90 & 10
\end{tabular}

\subsection{Characterization}

Tensile tests were performed in order to obtain tensile strength and elongation at break values of specimens by using Shimadzu AG-X Universal Testing Machine. Average tensile strength and elongation at break values of specimens were determined using five dumbbell-shaped samples for each composition of product at a constant crosshead speed of $5 \mathrm{~mm} / \mathrm{min}$, at ambient temperature.

Double edge notched tension (DENT) specimens were used for examining essential work of fracture (EWF) parameter of blends. Specimens were notched from both sides using milling cutter. Ligament lengths were milled from 6 to $14 \mathrm{~mm}$ and then the notches were sharpened using a curved knife to form a crack with crack tip radius of $<2 \mu \mathrm{m}$. EWF properties of specimens were tested on Shimadzu AG-X Universal Testing Machine at a constant crosshead speed of $2 \mathrm{~mm} / \mathrm{min}$, at ambient temperature.

\section{Results and discussion}

Figure 1 shows the load-extension curves of specimens. According to Fig. 1 it can be said that pure PPS exhibits brittle behavior. On the other hand, while elongation at break of pure PPS is about $3.5 \mathrm{~mm}$, this value increases to $32 \mathrm{~mm}$ with addition of $5 \mathrm{wt} . \%$ Lotader and increases to $34.5 \mathrm{~mm}$ with addition of $10 \mathrm{wt}$.\% Lotader.

Tensile strength and strain at break values of the samples are given in Figs. 2a and b. It can be concluded from Fig. 2a and b that while addition of $2 \mathrm{wt} . \%$ Lotader has decreased the tensile strength value of pure PPS by about $7 \%$, it has increased the strain at break value of PPS by about $98 \%$. However, Fig. 2a also shows that increasing Lotader content decreases the tensile strength

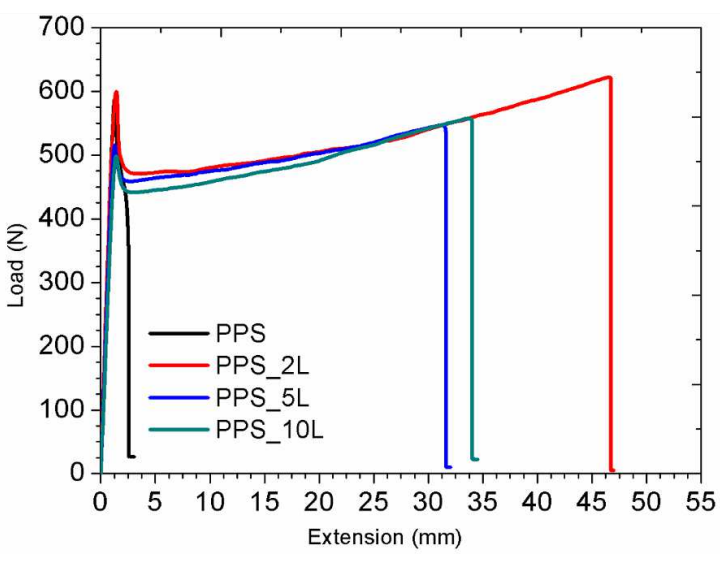

Fig. 1. Load-extension curves of samples.
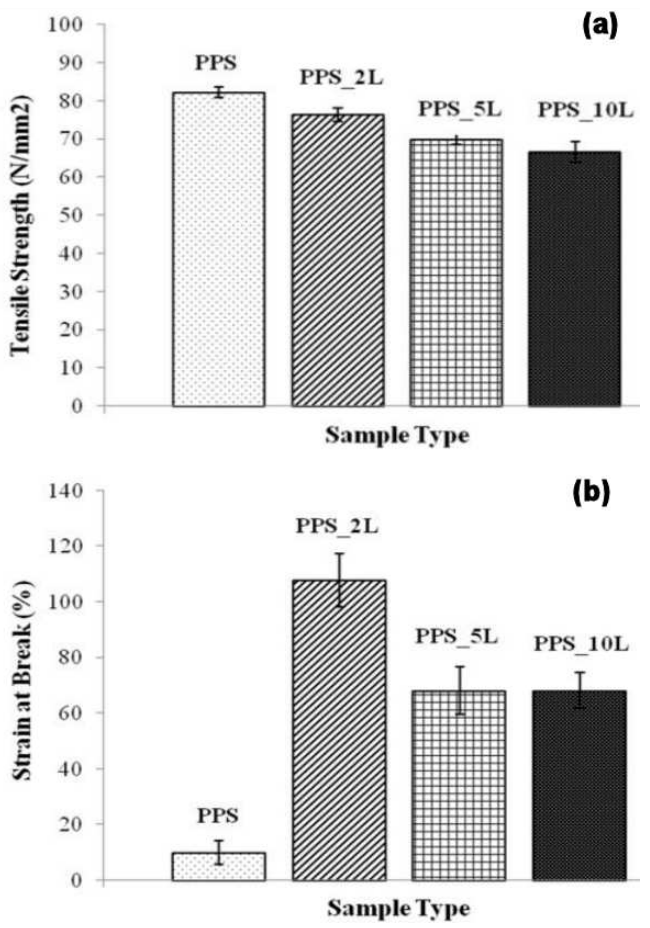

Fig. 2. (a) Tensile strength values and (b) strain at break vales of the samples.

of pure PPS. According to rule of mixture theory, if the percentage of one component increases, the mixture properties are likely to get similar to its properties. Hence it can be said that tensile strength of Lotader is lower than that of pure PPS. Thus, increasing Lotader amount decreases the tensile strength of sample. When considering both of the figures, it can be said that 2 wt.\% Lotader is an optimal loading level for obtaining optimal tensile strength and strain at break values.

Essential work of fracture (EWF) method has been widely used to evaluate the fracture toughness of ductile polymers or toughened polymers because of its experimental simplicity [9]. EWF method is based on supposition that total work of fracture $\left(W_{\mathrm{f}}\right)$ consists of two different deformation energies, in two obvious areas; the inner 
fracture zone $\left(W_{\mathrm{e}}\right)$, where the fracture occurs and outer plastic zone $\left(W_{\mathrm{p}}\right)$, where the plastic deformation takes place [10].

$$
W_{\mathrm{f}}=W_{\mathrm{e}}+W_{\mathrm{p}}
$$

$W_{\mathrm{e}}$ is energy that is related to the surface and $W_{\mathrm{p}}$ is related to volume. As a result, these energies can be written as

$$
\begin{aligned}
& W_{\mathrm{e}}=w_{\mathrm{e}} L t, \quad w_{\mathrm{e}}=W_{\mathrm{e}} / L t . \\
& W_{\mathrm{p}}=w_{\mathrm{p}} \beta L^{2} t, \quad \beta w_{\mathrm{p}}=W_{\mathrm{p}} / L^{2} t .
\end{aligned}
$$

Here $L$ is the ligament length, $t$ is the thickness of specimen, $w_{\mathrm{e}}$ is specific essential work of fracture and $w_{\mathrm{p}}$ is specific plastic work. If Eq. (2) and Eq. (3) are inserted into Eq. (1) we obtain

$$
w_{\mathrm{f}}=w_{\mathrm{e}}+\beta w_{\mathrm{p}} .
$$

The fracture toughness of pure PPS and Lotaderincluding PPS samples were evaluated using EWF method and results are given in Figs. 3 and 4 and in Table II. In order to evaluate the EWF data, first of all it is better to investigate the load-displacement curves which were obtained from DENT samples. Load-displacement curves of samples are given in Fig. $3 \mathrm{a}-\mathrm{e}$.
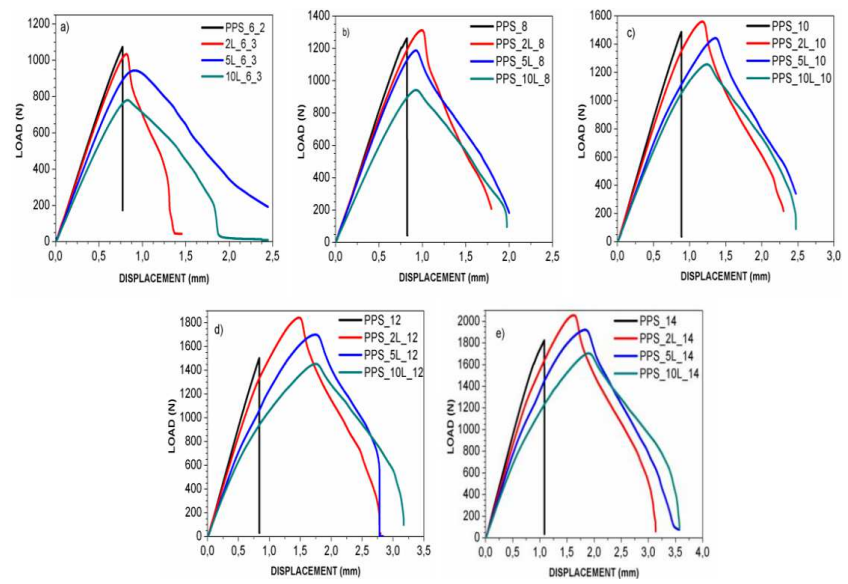

Fig. 3. Load-displacement curves of samples with ligament length of (a) $6 \mathrm{~mm}$, (b) $8 \mathrm{~mm}$, (c) $10 \mathrm{~mm}$, (d) $12 \mathrm{~mm}$, (e) $14 \mathrm{~mm}$.

Figure 3a-e show that pure PPS undergoes a brittle fracture. On the other hand the Lotader-including samples exhibit a ductile fracture. In addition to this, the samples including 5 wt.\% Lotader have absorbed the highest energy and have shown the biggest yielding area.

Curves of specific essential work of fracture versus ligament lengths are given in Fig. 4. The values of $w_{\mathrm{e}}$ and $w_{\mathrm{p}} \beta$ are also listed in Table II with the regression coefficients. It can be seen from Fig. 4 and Table II that a considerably low correlation coefficient and negative slope of regression line was obtained for pure PPS. The reason of this result was explained in the literature as uselessness of EWF method for these kinds of materials due to the failure mode (ductile-brittle) of the samples during loading [11]. On the other hand, good

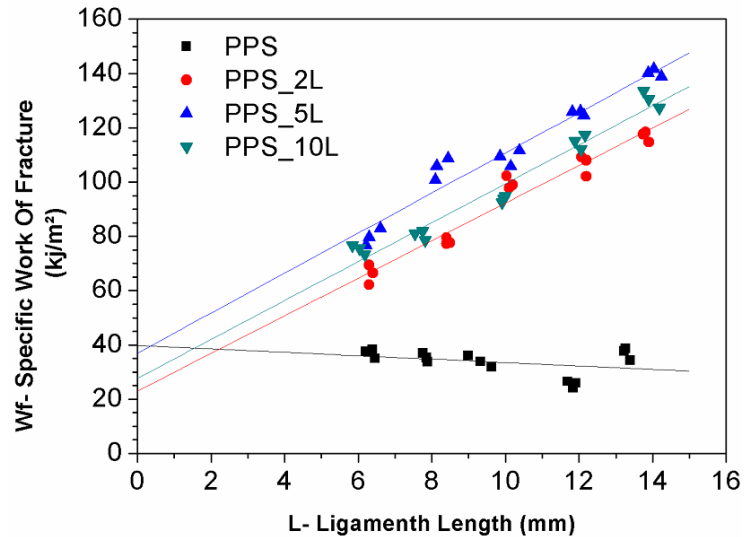

Fig. 4. Curves of specific essential work of fracture versus ligament lengths.

linear regressions with high correlation coefficients were obtained for Lotader-including samples. In addition to this samples including 5 wt.\% Lotader have exhibited the highest value of fracture toughness and further increasing the amount of Lotader decreases the fracture toughness. This results from the fact that Lotader acts as a crack initiator at concentrations above 5 wt.\% [12].

\section{TABLE II}

EWF data of samples.

\begin{tabular}{c|c|c|c}
\hline \hline Sample & $w_{\mathrm{e}}\left[\mathrm{kJ} / \mathrm{m}^{2}\right]$ & $w_{\mathrm{p}} \beta\left[\mathrm{MJ} / \mathrm{m}^{3}\right]$ & $R^{2}$ \\
\hline PPS & 39.78 & -0.63 & 0.0588 \\
PPS_2L & 23.01 & 6.92 & 0.9447 \\
PPS_5L & 36.96 & 7.37 & 0.94823 \\
PPS_10L & 27.64 & 7.17 & 0.955
\end{tabular}

\section{Conclusions}

According to tensile test results, it was found that tensile strength of pure PPS decreases slightly with increasing amount of Lotader. However addition of 2 wt.\% Lotader made a contribution to strain at break value of pure PPS. As a result it can be concluded that 2 wt.\% Lotader is an optimum loading level for obtaining optimum tensile strength and strain at break values. EWF method was used to assess the fracture toughness of samples. According to EWF test results it was found that Lotader addition changed the fracture manner of PPS from brittle to ductile. Fracture toughness of pure PPS improved for all three tested amounts of Lotader. However the maximum improvement was obtained for the PPS including 5 wt.\% Lotader. When all results are evaluated, it can be concluded that addition of 2 wt.\% Lotader makes contribution to fracture toughness value of pure PPS without considerably deteriorating the mechanical strength. Addition of 5 wt.\% Lotader makes a great contribution to fracture toughness of PPS and deteriorates the mechanical strength. 


\section{References}

[1] L. Juan, S. Tao, J. Thermoplast. Compos. Mater. 27, 594 (2014).

[2] A.E. Sahin, M.Sc. Thesis, Kocaeli University, 2013.

[3] J.Z. Liang, Polym.-Plast. Technol. Eng. 47, 1227 (2008).

[4] Y. Yang, H. Duan, S. Zhang, P. Niu, G. Zhang, S. Long, X. Wang, J. Yang, Compos. Sci. Tech. 75, 28 (2013).

[5] P. Cebe, Polym. Polym. Compos. 3, 239 (1995).

[6] D. Li, G. Qian, C. Liu, D. Wang, C. Chen, X. Zhao, J. Appl. Polym. Sci. 132, 41703 (2014).
[7] www.lotryl.com/export/shared/.content/ media/downloads/products-documentations/ altuglas-international/pof/lotader/ tds-lotader-ax8900.pdf.

[8] P. Martin, J. Devaux, R. Legras, M. Van Gurp, M. Van Duin, Polymer 42, 2463 (2001).

[9] S. Yilmaz, T. Yilmaz, A. Arici, J. Mater. Sci. 46, 1758 (2011)

[10] K. Zhang, G. Zhang, B. Liu, X. Wang, S. Long, J. Yang, Compos. Sci. Technol. 98, 57 (2014).

[11] T. Bárány, T. Czigány, J. Karger-Kocsis, Prog. Polym. Sci. 35, 1257 (2010).

[12] M. Mehrabi Mazidi, M.K. Razavi Aghjeh, F. Abbasi, J. Mater. Sci. 47, 6375 (2012). 